\title{
The Design And Implementing Of Collaborative Learning On Internet Curriculum Development
}

\author{
Chengling Zhao, Li Lin \\ Information Technology Department Central China Normal University, \\ Wuhan, Hubei, 430079 \\ E-MAIL: zhcling@mail.ccnu.edu.cn \\ E-MAIL: linli_198288@163.com
}

\begin{abstract}
In the distant education, the learning of internet curriculum is widespread concerned by people. In order to promote internet curriculum learning, completing task cooperatively is the effective learning manner. In this article, writer expounds the concept of collaborative learning, and explains the implementing structural flow diagram of collaborative learning on internet curriculum. At last, writer analyzes the practice steps on collaborative learning concretely which are based on The expanding of Junior middle school scientific curriculum.
\end{abstract}

With the development of informational society, the core technique of modern distant education by multimedia and internet is the new mode of education, also is widespread accepted by people. When we talk about modern distant education, it's naturally to reflect internet education. The learning of internet curriculum also becomes the most important part of distant education. The superiority of internet is communication and interchange, and collaborative learning is just right embodying it The writer just concisely expounds the collaborative learning on internet curriculum and analyzes the practice steps on collaborative learning concretely which is based on 《The expanding of Junior middle school scientific curriculum》.

\section{Collaborative learning and collaborative learning with internet environment}

Constructivism theories of learning deem: learning is the process that learners initiatively construct innate psychology characteristic in the mutual mechanism of learners and environment. This theory puts emphasis on regarding learner as the

Please use the following format when citing this chapter:

Zhao, C., Lin, L., 2007, in IFIP International Federation for Information Processing, Volume 252, Integration and Innovation Oricnt to E-Socicty Volume 2, cts. Wang, W., (Boston: Springer), pp. 355-363. 
centre, and thinks that "situation", "cooperate ", "conversation" and "resource" is the basic element and character in the constructivism learning environment. Moreover collaborative learning is developed at the base of this theory. [1]

\subsection{Collaborative learning}

In the information society, people have put forward higher requirement to quality. Constructivism is just the basic theory of collaborative learning. In the process of collaborative learning, the learners are just through interchange and communication with partners and teachers to obtain knowledge. In this way, they can achieve the further comprehension of question and knowledge, thus let the knowledge storage in the cerebrum long-term. Collaborative learning is a teaching method that some students finish the learning through group. Between the learners, they have the harmonious relationship, corporate attitude, and they share the information and resources, undertake to study the task together. Only in this way, they can achieve the common learning target. It can say: collaborative learning is the corporate process, also is the process to emerge the personal glamour.

\subsection{Collaborative learning in the internet environment}

Collaborative learning at the base of internet is the process. It uses computer internet, multimedia and other relative technique. In this process, most learners aim directly at the same learning task to interchange and cooperate with each other to attain the further understanding and grasping the teaching content. [2]

In the learning of internet curriculum, communication between teachers and learners, and learners with each other need internet. Now the roles of teachers are resources designers, teaching mentors and evaluator. Teaching tasks' allocation and clarification, and teaching processes' control can be supported by computer internet.

From the knowledge of collaborative learning and the view of learning, we can divide the collaborative learning on internet curriculum into four steps: analyzing learners' characteristic, grouping, processing of learning and evaluating. The mode of it also has: competition, cooperation, partner, designer and role playing. People who learn about internet curriculum are in the different direction. In order to finish the same learning task corporately, they can discuss and learn with groups at the environment of computer internet. In the process, the groups can share the information with other learners that they explore in the learning process.

\section{Collaborative learning in the in ternet curriculum exploitation}

The study of internet curriculum is mainly on individual learning. In order to attain good learning effect and grasp more knowledge, Internet curriculum can launch collaborative learning. 


\subsection{The character of internet curriculum}

(1)Can't control by the time and space

Because the internet curriculum is on the Internet, and can be obtained whenever and wherever possible through the terminal station of the network, so the learners can study on time unrestrictedly. The learners who are in the different time and space can study with their own needing. Even if the internet curriculum is synchronous teaching, the learners are also free on space. Carrying on asynchronous teaching, the learner has the larger degree of freedom on the time and space.

(2) Resource sharing

Internet teaching resource is different from the traditional one. It takes books, newspapers and periodicals, tape, broadcast, TV, etc. as material carrier. Internet education resource is a kind of digitized resource taking electronic network as carriers and media of transmitting. These resources are suitable for network users' visiting at any time, and needn't be influenced by carrier quantity information like traditional education.

(3) Easy to cooperation

The study of internet curriculum may not be restricted by space-time to interchange and discuss. Also it can also utilize the appropriate software tool to support and create in coordination. A lot of online education platforms can support learners to carry on exchanging and information sharing.

(4) Multi-way interaction

Under this multi-way interactive, from the viewpoint of students, we can make use of the network resource to study and produce interaction on one hand; On the other hand can talk with teachers, companions, experts and produce interaction through the resources of network.

\subsection{Collaborative learning in the internet curriculum exploitation}

(1) Cultivating the habit of learning, and guaranteeing the teaching effect

Bring up the ability of students' study independently should run through all the study process. But, because of the influence by the long-term exam-oriented education, a lot of students in our country get used to studying passively, and get used to teachers' inculcating to study. When they enter into university, students can't adapt to the new network teaching form of study independently. And this situation has influenced the results of learning seriously. In order to help students to change this study method, collaborative learning plays a good transition role. It enables students to train the habit of independent study in the course of studying in coordination, and strengthen the ability of independent study progressively. [3]

(2) Breaching the limitation, and extruding interaction

For the single student, his learning ability, knowledge level has some limitation. When they meet the obstacle in the learning of internet curriculum, they'll spend a lot of time and energy on overcoming them even if they can work hard to overcome. But collaborative learning can just make up the limitation of individual study. Through collaborative learning, learners will cooperate with each other, learn from other's strong point to offset one's weakness, and interchange with each other to overcome the learning difficulty corporately. In this way, learners can learn more useful knowledge faster and finer. Even more, if let individual study as the unique 
learning method in the internet curriculum. On one hand, it can be short of communication with students and teachers, also, between students. As that situation, learners will be in their own thinking range long-term and won't obtain more information and train of thought extensively. On the other hand, individual study long-term may lead to learning tiredness, and now the request of learning target may not be finished on time and quality. In the environment of collaborative learning, students have more and more interchange and communicate with teachers also with each other. It makes the significance constructive coming true from easy to complicate in the learning as learners of the center. It promotes the learners to study finer. Not only cultivate the students' thinking ability, the ability of studying on one's own, also it is helpful to promote the corporate spirit of the students. It's useful to promote the development of students' high perception and the shaping of healthy sentiment.

\section{The design and implementing of collaborative learning in the internet curriculum exploitation}

\subsection{Design of collaborative learning in the internet curriculum exploitation}

According to the teaching requirement of implementing of collaborative learning on internet curriculum, I provide brief implementing flow diagram in coordination. The following Fig. 1 shows.

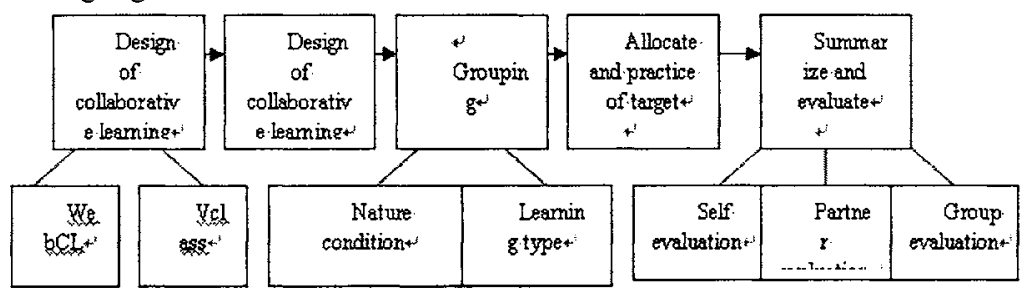

Fig. 1

In the near future, we have been finished the curriculum 《The expanding of junior middle school scientific curriculum》. It can be the case of collaborative learning on internet curriculum. The purpose of this curriculum is to promote the teacher's lifetime study, and offer abundant resources for the teachers in the middle and primary schools of learning and teaching, and offer the theory and practice for the first line teachers who are engaged in teaching of course of 《Science》.Through learning the resources of this curriculum, teachers can understand how to teach

《Science》 well and really grasp the teaching method of scientific knowledge. In this way, they can adapt to the teaching of 《Science》 as soon as possible, and improve self's specialization level. In order to implementing teaching in the 《Science》, teachers, in the different area, have the necessity of launching collaborative learning. 
This course has five units, analyze of curriculum standard and teaching material, expand of the life science field knowledge, expand of the matter science field knowledge, expand of the earth, the universe and space science field knowledge, and research of the science studies method.

The learning of this curriculum, (Fig. 2) we can adopt the scheme of individual learning. But in order to let teachers implement teaching quickly, collaborative learning can improve the target coming true.

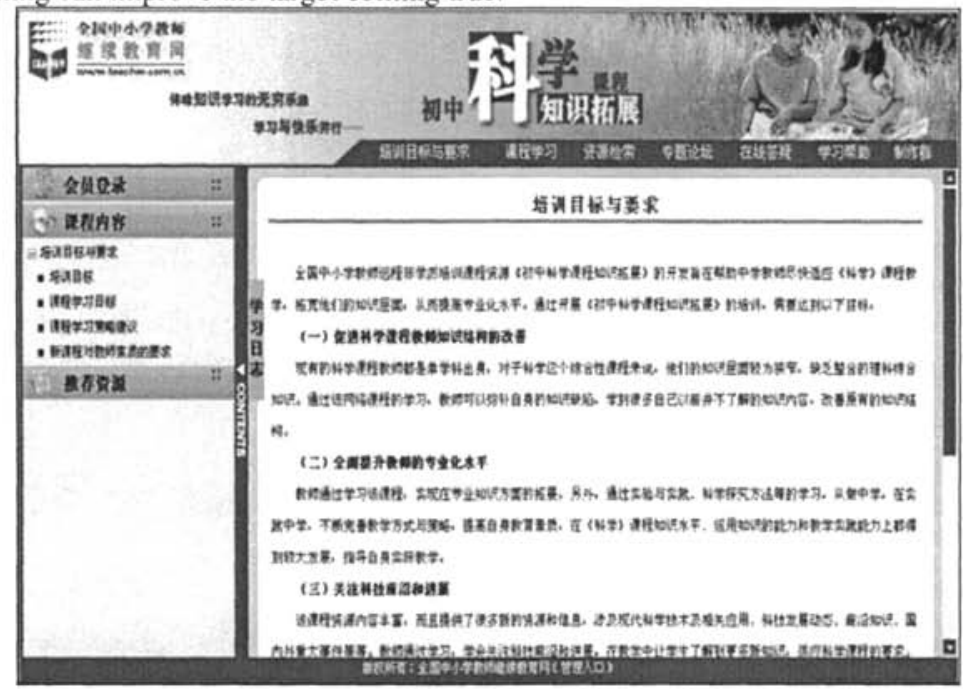

Fig. 2

\subsection{The implementing of collaborative learning in the internet curriculum exploitation}

Next, we will give the practice steps concretely and analyze briefly of collaborative learning which is based on 《The expanding of junior middle school scientific curriculum》.

(1) Design of collaborative learning

In order to collaborate to learn on internet curriculum, it needs the corporate learning environment based on network. Also it's the corporate environment that draw assistance from computer with distributing handling technique, multimedia technique, database technique, correspondence technique and network technique. The Web-based Cooperative learning that advanced by Ronghuai Huang in his doctor thesis of Beijing Normal University can be this environment. So it is Vclass. With the development of technology, it appears some assistant method to support interchange activity, for example, E-mail, BBS, ICQ. The fourth generation of interchanging method Blogging also becomes the good helper to launch collaborative learning.

In this course, the blogging(Fig.3) in the special subject forum provides a very good exchanging platform and material base for studying in coordination. It can be 
the bridge and passage of the exchanging between with students and teachers, also between students.
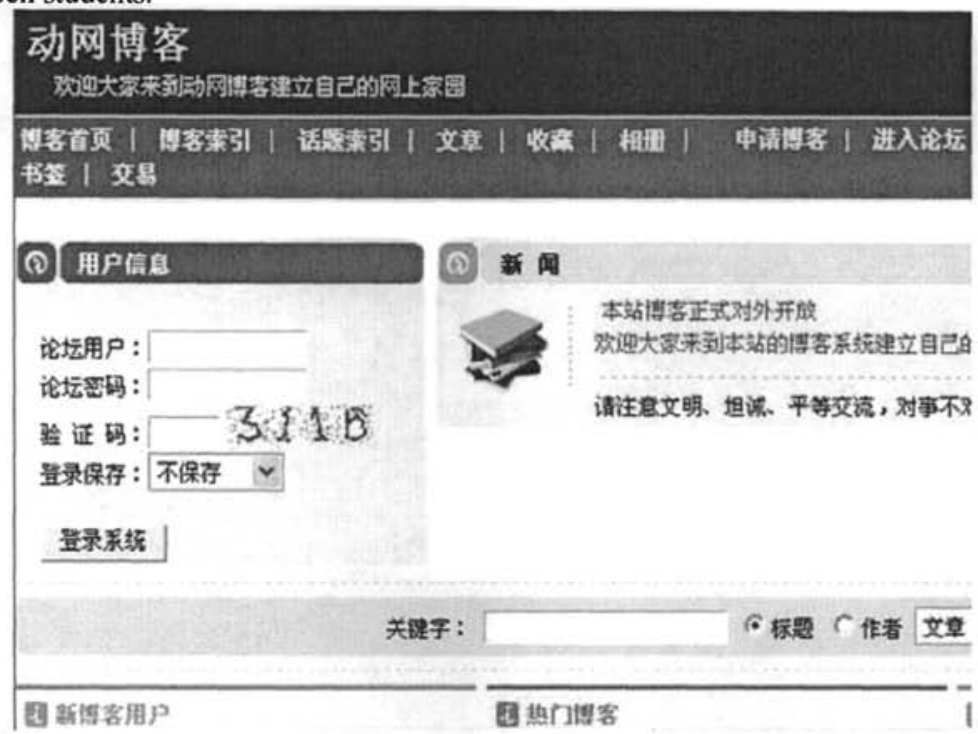

\section{Fig.3}

(2) Establish of learning target

Learning target is the prerequisite of learning, also is the navigation. Of course, not all of the internets curriculums are adapt to collaborate to learn. It needs teachers to choose some suitable contents, which depending on the teaching target and students' development situation to define the overall target. Then teachers resolve it and allocate the assignment to each student.

In the 《The expanding of Junior middle school scientific curriculum》, analyze of curriculum standard and teaching material, expand of the life science field knowledge, expand of the matter science field knowledge, expand of the earth, the universe and space science field knowledge, and research of the science studies method are the main composing of the special subject forum. Every thesis has small discussion topics.( Fig.4) In the training goal and requirement, we give the learning requirement concretely. 


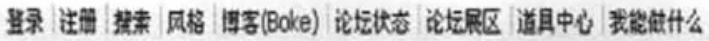

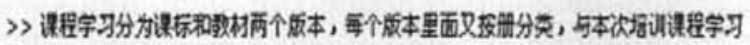

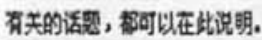

\begin{tabular}{|c|c|c|}
\hline \multicolumn{3}{|c|}{ 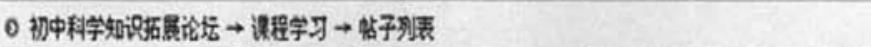 } \\
\hline \multirow{3}{*}{\multicolumn{2}{|c|}{ 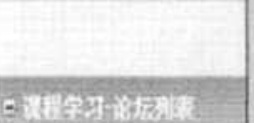 }} & H谓示与数材分析 \\
\hline & & 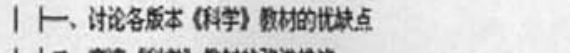 \\
\hline & & 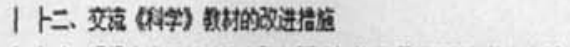 \\
\hline \multirow{5}{*}{ 루 } & 课标与基本分析 (3) & 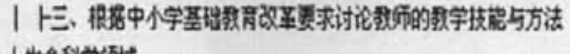 \\
\hline & 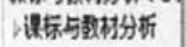 & 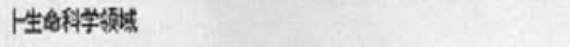 \\
\hline & & 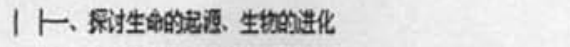 \\
\hline & 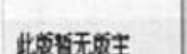 & 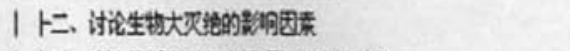 \\
\hline & & 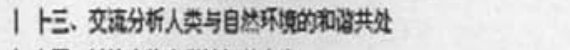 \\
\hline \multirow{4}{*}{ (2) } & 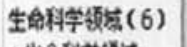 & I H四, 讨论生物多样珄祖关内容 \\
\hline & 生稀科学的琙 & 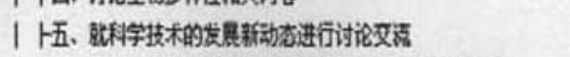 \\
\hline & & 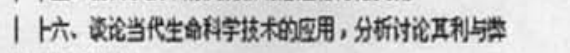 \\
\hline & 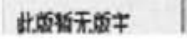 & 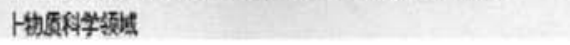 \\
\hline
\end{tabular}

Fig.4

(3) Grouping

The process of grouping makes the learners the single condition into the corporate one .It has some restriction of group. Firstly, it depends on the character of nature condition. [4] Learners on the network have different from region, age, the structure of knowledge learning. Getting this information can through questionnaire, answer questions and so on. We can allocate reasonably as the learners have more difference, so that they can make progress together in the corporate discussing. Secondly, it depends on the character of learning type. [4] It means the learning habit and perception characteristic. In the group of collaborative learning, it can let the students with different type in the same learning group, that it's good for learners interchange and self-identity with each other. At the same time, grouping should base on learning content. Let the learners who are adapting to study the same learning content in the same group. This manner is helpful for them to grasp and absorb knowledge.

In the process of learning, teachers can go into the forums according to their own needing. So they can interchange and communicate with other learners, in order to reach the deeper understanding of the knowledge. Also they can be leaded with expert, and be grouped according to there area and their teaching subject.

(4) Allocate and practice of target

The allocation of corporate target should consider every members' characteristic, and bring into full play of their own good points. It needs for them to know their important in the grouping and increase their own feeling of responsibility. After allocating the target, the members should go their own way, and undertake their own learning target. They can search the documents through network, read, analyze, organization the date, then shape their own view and share with other members in the group. Through online to discuss and study to obtain knowledge.

When every teacher makes sure the group, they can choose the target 
according to their own predominance. It's also the learning target that the learners should be taken on and the knowledge that the learners should be interchanged and communicated with each other in the collaborative learning. In this process, all learners ought to realize the significance in the collaborative learning and give the practice steps according to the learning target. Then form self cognition and understanding of that part knowledge in the step-by-step accumulation. In this way, the learners can interchange and communicate with other learners.

(5) Summarize and evaluate

Evaluation is the important step of collaborative learning. The more evaluation has, the bigger progress will make. The content of evaluation is from the learning target's finishing situation and corporate situation of the learners on the collaborative learning. It should not only evaluate the results of learning, but also process of learning. In the group of collaborative learning, it can have self-evaluation, partner evaluation and group evaluation. Of course, the teachers should instruct the evaluation process. The evaluation of collaborative learning should from more directions. And performance of the personal task, behavior while cooperating, expression and discussing in the achievement showing should bring into the evaluation index system. [5]

Summarizing and evaluating are the most important part in the collaborative learning. In the learning of 《The expanding of Junior middle school scientific curriculum》, summarizing and evaluating are the important stage to promote the personal knowledge level and form the studying experience. Finishing the learning, the learners that are the teachers who learn the curriculum should self evaluate first. In the learning page, it has study daily record button rolling with the page. Clicking the mouse can see that button. (Fig.5)

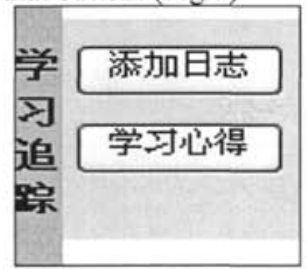

Fig.5

This part notes the learning situation of the learners. It can be the good basis and reference in the self evaluation. Next it's the partner evaluation. It's the communication with the partner after learning. It's helpful to absorb knowledge and accumulate experience for learners. Last, in the group of collaborative learning, there has the necessity to launch group evaluation. In this process, we usually consider the learners' contribution in the group and whether the learners can share the learning target with other learners or not. It's also the interchange and communication situation with the members. All the evaluation can be come true in the forum.

\section{Conclusion}

Modern distant education is the new teaching method in the informational society. Internet curriculum is the most important part in the distant education. Corporation in the internet curriculum becomes the effective learning method based on the character 
of internet curriculum. Collaborative learning in the internet curriculum exploitation is cultivating the habit of learning by oneself and guaranteeing the teaching effect. Also it offsets the shortage of individual study in the internet curriculum learning, and extrudes the interaction and communication. Writer gives the five steps implementing flow diagram, and analyze the implementing concretely based on the 《The expanding of junior middle school scientific curriculum》. It's useful for the actualization of collaborative learning on the internet curriculum. The students launching the learning on the internet are the process of exhibiting one's strong suit, also the process of promoting one's integration ability. So the implementing of collaborative learning on internet curriculum should be the focus for us.

\section{References}

1. Kekang He. Instructional Technology. Publishing house of Beijing Normal University (2002).

2. Yanping Wang. Design of the cooperating virtual learning environment of network . Education technology guide, 2006,(7).

3. Gang Peng. Individual learning and collaborative learning on network teaching . Education technology guide, 2006,(7).

4. Fei Dong. The collaborative learning research of adult studies based on network . China's adult education, 2006, (6).

5. Qiuhong Geng. The discussion of collaborative learning environment based on network. Science and Education Information, 2006,(9). 